\title{
O repertório pianístico dos programas de recitais de alunos da EMEM (2001 -2010)
}

\author{
The piano repertory of EMEM students recital \\ programs (2001-2010) \\ JOÃO COSTA GOUVEIA NETO (D)
}

LUISIANE CRISTINA SÁ DE ALMEIDA (Db

\section{Resumo}

O ensino e estudo do piano continuam despertando interesse nas pessoas de várias faixas etárias ao longo do território brasileiro e na capital maranhense não é diferente. Desde o século XIX já havia professores de piano em São Luís e essa tendência continua ao longo do século XX, com a institucionalização de uma escola técnica de música pelo governo do Estado do Maranhão, na qual há o curso de piano funcionando com regularidade até hoje. Nesse sentido, este artigo objetiva analisar o repertório executado nos recitais pelos alunos do referido Curso entre $2001 \mathrm{e}$ 2010, a partir dos programas, com vistas a mapear quais compositores são mais executados e se há mudanças entre o repertório utilizado no século XIX para o do XXI.

Palavras-chave: Repertório. Recital de piano. EMEM.

\begin{abstract}
The teaching and study of the piano continues to arouse interest in people of various age groups throughout the Brazilian territory and in the capital of the State of Maranhão is no different. Since the 19th century, there have been piano teachers in São Luís and this trend continues throughout the 20th century, with the institutionalization of a technical music school by the government of the State of Maranhão, in which there is a regular piano course until today. In this sense, this article aims to analyze the repertory performed in the recitals by the students of that Course between 2001 and 2010, based on the programs, in order to map which composers are most performed and whether there are changes between the repertoire used in the 19th century for that of the XXI.
\end{abstract}

\footnotetext{
${ }^{a}$ Universidade Estadual do Maranhão (UEMA), São Luís, MA, Brasil. Doutorando em Educação, na linha de pesquisa Educação, Cultura e Sociedade pela Universidade Federal do Pará (UFPA), e-mail: rairicneto@yahoo.com.br

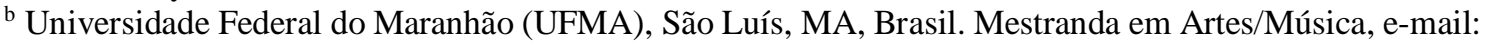
luisianesalameida@gmail.com

Rev. Caminhos da Educação: diálogos, culturas e diversidades, Teresina, v. 3, n. 1, p. 103-124, Jan./Abr. 2021
} 
Orepetório pianístico dos programas de recitais de alunos da EMEM(2001 -2010)

Keywords: Repertory. Piano recital. EMEM.

\section{Resumen}

La enseñanza y el estudio del piano sigue despertando el interés de personas de diversas edades en todo el territorio brasileño y en la capital de Maranhão no es diferente. Desde el siglo XIX, hubo profesores de piano en São Luís y esta tendencia continúa a lo largo del siglo XX, con la institucionalización de una escuela técnica de música por parte del gobierno del estado de Maranhão, en la que hay un curso regular de piano hasta la fecha actual. En este sentido, este artículo tiene como objetivo analizar el repertorio interpretado en los recitales por los alumnos de ese Curso entre los años de 2001 y 2010, en función de los programas, con el fin de mapear qué compositores son más interpretados y si hay cambios entre el repertorio utilizado en el siglo XIX por el del XXI.

Palabras clave: Repertorio. Recital de piano. EMEM.

\section{Introdução}

O século XXI continua trazendo muitas inquietações relativas às práticas e padrões de ensino-aprendizagem empregados nas instituições encarregadas no ensino específico da música, no que tange à preservação de um tipo de repertório do século XIX e primeiras décadas do século XX que em muitos casos não dialoga mais com a realidade atual e local onde essas escolas estão inseridas. Apesar de as instituições dedicadas ao ensino de música terem as especificidades relativas ao próprio ensino dos instrumentos que fazem parte do seu programa de formação técnica, os repertórios poderiam se relacionar com mais intensidade às realidades locais, contribuindo assim para o fortalecimento da sua cultura ao formar instrumentistas.

O lugar de onde escrevemos este artigo e a partir do qual fazemos nossas inferências e análises é o Curso Técnico de Piano da Escola de Música do Estado do Maranhão -EMEM, situada em São Luís, capital do Estado, sendo ainda a única escola estadual reconhecida para formar pianistas em nível técnico no Maranhão.

Para alcançar os objetivos propostos neste artigo utilizamos pesquisa bibliográfica de cunho qualitativa, pois é "uma abordagem sistemática, cujo objetivo principal é compreender as qualidades de um fenômeno específico, em um 
determinado contexto" (ILARI, 2007, p. 37, apud PENNA, 2015, p.99), sendo desse modo uma pesquisa de caráter interpretativo. Além da pesquisa qualitativa, utilizamos a pesquisa-ação (TRIPP, 2005) visto que os autores são partícipes da pesquisa em questão, por serem ex-alunos do Curso Técnico de Piano da EMEM e por terem participado dos recitais como executantes no período em questão.

As principais fontes desta pesquisa são os programas dos recitais de piano (solo/coletivo) realizados no Auditório José Ribamar Belo Martins ${ }^{i}$ da atual Escola de Música do Estado do Maranhão - EMEM, entre os anos de 2001 e 2010, sendo consultados 22 folders. Para responder a uma das inquietações deste artigo utilizamos também os Programas do Curso Técnico de Piano da referida Escola dos anos de 2007 e 2018, pois indicam qual o repertório obrigatório deve ser apresentado pelos alunos do Curso não somente nos recitais, mas também qual tipo formação pianística a Escola oferece. A análise das fontes consistiu no levantamento de compositores a partir do período romântico presentes nos programas dos recitais de piano, para verificar se eles constam no repertório do Programa do Curso Técnico do referido instrumento, cujos resultados serão apresentados ao longo deste artigo.

\section{O Curso Técnico de Piano da EMEM}

A criação da Escola de Música em São Luís do Maranhão é marcada por três períodos distintos. A primeira instituição oficial púbica surge no início do século XX, por meio da Lei $\mathrm{N}^{0}$ 280, de 10 de abril de 1901, denominada Escola de Música Estadual, com sede na Rua Grande, Centro de São Luís. Teve como primeiro diretor da instituição, o tenor maranhense Antônio Rayolii (GOUVEIA NETO, 2012), cuja gestão ocorreu de 1901 a 1904. A escola ofertava ensino gratuito de música e solfejo, canto coral e canto solo, violino, flauta, clarinete e oboé, e piano elementar no período noturno. Após a morte precoce de Antônio Rayol em 1904, a Escola de música deixou de exercer suas atividades (GOUVEIA NETO; NAVARRO; CASTRO, 2019). A segunda ocorreu em 1907, com um novo nome Escola de Música do Estado do Maranhão, esta foi reorganizada a partir do Decreto No 69, de 26 de julho de 1907. Entre 1907 e 1911 o diretor da instituição foi o compositor maranhense João Nunesiii, 
além de ter sido professor de piano da escola. Por sua vez, a escola de música foi novamente fechada em 1911 pelo governo do Maranhão (SILVA, 2015).

Após 60 anos de fechamento da escola de música, somente na segunda metade do século XX surge a terceira e atual Escola de Música do Estado do Maranhão (EMEM), a partir do Decreto-Lei No 5.267, de 21 de janeiro de 1974, no governo de Pedro Neiva de Santana, iniciando suas atividades musicais em 13 de maio de 1974. A pianista maranhense Maria José Duailibe Cassas Gomesiv, assumiu o cargo de direção da instituição. A EMEM foi reinaugurada em 18 de abril de 2001, em uma nova sede situada na Rua da Estrela/Giz, No 363, Centro Histórico de São Luís/MA (sede 4 e atual), com um novo nome oficial Escola de Música do Estado do Maranhão - Lilah Lisboa de Araújo (EMEM), um sobrado colonial do século XVIII, Solar Santa Terezinha, que foi a residência da pianista Lilah Lisboa de Araújov (FERREIRA, 2017).

A EMEM, instituição pública estadual, é reconhecida pelo Conselho Estadual de Educação, com Resolução No 274/1981. Atualmente seu corpo docente é constituído por professores efetivos aprovados em concurso público na área da música e por professores contratados por meio de seletivo. Muitos desses professores foram ex-alunos da instituição, possuindo em sua formação além do Curso Técnico em Instrumento, Licenciatura em Música entre outras graduações, Bacharelado, Especialização, Mestrado e um professor aposentado com doutorado em música. Segundo Ferreira (2017) “[...] a EMEM oferece o curso de Musicalização Infantil e 19 modalidades instrumentais. Essas modalidades são ainda subdivididas em Técnico e Fundamental, e este, em adulto e infantil [...]" (FERREIRA, 2017, p. 125) grifo nosso.

Tendo como base os editais publicados para seleção de novos alunos na EMEM entre 2015 e 2020, os instrumentos ofertados nos Cursos Fundamental Infantil e Adulto e Curso Técnico são os seguintes: bandolim vi, bateria, canto, cavaquinho, clarinete, contrabaixo acústico, contrabaixo elétrico, flauta doce e transversa, guitarra elétrica, percussão, piano, saxofone, trombone, trompa, trompete, 
tuba, violão clássico/erudito vii e popular, violino e violoncelo. A escola funciona nos turnos matutino e vespertino, cujo ingresso de novos alunos se dá mediante a processo seletivo.

No que se refere ao instrumento musical cujo repertório é objeto desta pesquisa, O Curso de Piano da EMEM é constituído pelo Curso Fundamental Infantil (09 a 13 anos), Curso Fundamental Adulto (a partir de 14 anos) e Curso Técnico Profissionalizante, de nível médio (a partir de 15 anos). Para o presente artigo analisamos os Programas do Curso Técnico de Piano, de 2007 (Piano Técnico I-X), pois os programas dos recitais de piano estão atrelados a esse currículo e o de 2018 (Piano Técnico I-VI), conforme quadro 1, para analisar se houve mudanças somente o que diz respeito ao repertório pianístico, que corresponde aos compositores, obras e gêneros de cada período musical.

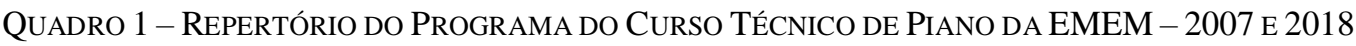

\begin{tabular}{|c|c|c|c|}
\hline & Curso Técnico de Piano 2007 & Curso Técnico de Piano 2018 & \\
\hline $\begin{array}{l}\text { Piano } \\
\text { Técnico } \\
\text { I }\end{array}$ & $\begin{array}{l}\text { Duração - } 1 \text { semestre: } \\
\text { Repertório [obrigatório]: Alice } \\
\text { Botelho, Meu Piano é Divertido v. } \\
1 \text { (completo); } \\
\text { Leila Fletcher, The Leila Fletcher } \\
\text { Piano Course v.1 (adulto ou } \\
\text { infantil-completo). }\end{array}$ & ------ & ----- \\
\hline $\begin{array}{l}\text { Piano } \\
\text { Técnico } \\
\text { II }\end{array}$ & $\begin{array}{l}\text { Duração - } 1 \text { semestre: } \\
\text { Repertório [obrigatório]: Alice } \\
\text { Botelho, Meu Piano é Divertido v. } \\
2 \text { (completo); } \\
\text { Leila Fletcher, The Leila Fletcher } \\
\text { Piano Course v. } 2 \text { (completo). }\end{array}$ & ------ & ----- \\
\hline $\begin{array}{l}\text { Piano } \\
\text { Técnico } \\
\text { III }\end{array}$ & $\begin{array}{l}\text { Duração - } 1 \text { semestre: } \\
\text { Repertório [obrigatório]: J. S. Bach, } \\
\text { Livro de Ana Magdalena Bach - } 1 \\
\text { lição. } \\
\text { Repertório [livre]: } 1 \text { (obrigatória) } \\
\text { ou } 2 \text { (opcional). }\end{array}$ & ------ & ------ \\
\hline $\begin{array}{l}\text { Piano } \\
\text { Técnico } \\
\text { IV }\end{array}$ & $\begin{array}{l}\text { Duração - } 1 \text { semestre: } \\
\text { Repertório [obrigatório]: J. S. Bach, } \\
\text { Livro de Ana Magdalena Bach }-2 \\
\text { peças; R. Schumann, Álbum para a } \\
\text { Juventude - } 1 \text { peça. } \\
\text { Repertório [livre]: peças de } \\
\text { repertório - } 2 \text { obrigatórias. }\end{array}$ & ------ & ----- \\
\hline $\begin{array}{l}\text { Piano } \\
\text { Técnico } \\
\text { V }\end{array}$ & $\begin{array}{l}\text { Duração - } 1 \text { semestre: } \\
\text { Repertório [obrigatório]: J. S. Bach, } \\
\text { Livro de Ana Magdalena Bach }-2 \\
\text { peças; (conclusão desse livro); } \\
\text { Schumann, Álbum para a Juventude } \\
-2 \text { lições; Sonatina (Clementi, } \\
\text { Diabelli, Kuhlau, Gurlitt, } \\
\text { Beethoven), } 1 \text { completa. }\end{array}$ & $\begin{array}{l}\text { Duração - } 1 \text { semestre: } \\
\text { Repertório [obrigatório]: J. S. Bach, } \\
23 \text { Peças Fáceis ou Pequenos } \\
\text { Prelúdios }-2 \text { peças: } 2 \text { prelúdios ou } 1 \\
\text { prelúdio e } 1 \text { invenção a } 2 \text { vozes; } 1 \\
\text { Sonata Barroca; R. Schumann, } \\
\text { Álbum para a Juventude }-1 \text { peça. }\end{array}$ & $\begin{array}{l}\text { Piano } \\
\text { Técnico } \\
\text { I }\end{array}$ \\
\hline
\end{tabular}




\begin{tabular}{|c|c|c|c|}
\hline & $\begin{array}{l}\text { Repertório [livre]: } 1 \text { peça } \\
\text { obrigatória, pedalizada. }\end{array}$ & $\begin{array}{l}\text { Repertório [livre]: } 1 \text { obra de autor } \\
\text { estrangeiro e } 1 \text { obra de autor } \\
\text { brasileiro. }\end{array}$ & \\
\hline $\begin{array}{l}\text { Piano } \\
\text { Técnico } \\
\text { VI }\end{array}$ & $\begin{array}{l}\text { Duração - } 1 \text { semestre: } \\
\text { Repertório [obrigatório]: J. S. Bach, } \\
23 \text { Peças Fáceis, } 1 \text { peça; Schumann, } \\
\text { Álbum para a Juventude, } 2 \text { peças; } \\
\text { Sonatina, Clementi (exceção: op. } \\
36 \text { n }^{\circ} \text { 1), Diabelli, Beethoven } \\
\text { (exceção: Sonatina em Sol M), } \\
\text { Kuhlau - } 1 \text { completa. } \\
\text { Repertório [livre]: } 1 \text { peça } \\
\text { obrigatória. }\end{array}$ & $\begin{array}{l}\text { Duração - } 1 \text { semestre: } \\
\text { Repertório [obrigatório]: J. S. Bach, } \\
23 \text { Peças Fáceis ou Pequenos } \\
\text { Prelúdios }-2 \text { prelúdios, ou } 1 \\
\text { prelúdio e } 1 \text { Invenção a } 2 \text { vozes, ou } \\
2 \text { Invenções a } 2 \text { vozes; } 1 \text { Sonata } \\
\text { Barroca; R. Schumann, Álbum para } \\
\text { a Juventude - } 1 \text { peça (exceto as mais } \\
\text { fáceis do livro). } \\
\text { Repertório [livre]: } 1 \text { obra de autor } \\
\text { estrangeiro e } 1 \text { obra de autor } \\
\text { brasileiro. }\end{array}$ & $\begin{array}{l}\text { Piano } \\
\text { Técnico } \\
\text { II }\end{array}$ \\
\hline $\begin{array}{l}\text { Piano } \\
\text { Técnico } \\
\text { VII }\end{array}$ & $\begin{array}{l}\text { Duração - } 1 \text { ou } 2 \text { semestres: } \\
\text { Repertório [obrigatório]: J. S. Bach: } \\
23 \text { Peças Fáceis, } 2 \text { peças (exceto } \\
\text { Prelúdio em Dó M); Schumann, } \\
\text { Álbum para a Juventude }-1 \text { peça } \\
\text { (conclusão); Sonatina }-1 \text { completa. } \\
\text { Repertório [livre]: } 1 \text { peça. }\end{array}$ & $\begin{array}{l}\text { Duração - } 1 \text { semestre: } \\
\text { Repertório [obrigatório]: J. S. Bach, } \\
1 \text { invenção a } 2 \text { vozes ou } 1 \text { prelúdio e } \\
\text { fugueta; } 1 \text { Sonata Clássica (Haydn } \\
\text { ou Beethoven op. } 49 \mathrm{n}^{\circ} 1 \text { e } 2 \text { ); R. } \\
\text { Schumann, Álbum para a Juventude } \\
-1 \text { peça (exceto as mais fáceis do } \\
\text { livro). } \\
\text { Repertório [livre]: } 1 \text { obra de autor } \\
\text { estrangeiro; } 1 \text { obra de autor } \\
\text { brasileiro. }\end{array}$ & $\begin{array}{l}\text { Piano } \\
\text { Técnico } \\
\text { III }\end{array}$ \\
\hline $\begin{array}{l}\text { Piano } \\
\text { Técnico } \\
\text { VIII }\end{array}$ & $\begin{array}{l}\text { Duração - } 1 \text { ou } 2 \text { semestres: } \\
\text { Repertório [obrigatório]: J. S. Bach, } \\
2 \text { invenções a } 2 \text { vozes } \\
\text { (obrigatoriedade de tocar apenas } \\
\text { uma no recital); Sonata, } 1 \text { sonata } \\
\text { solo completa (Haydn, Mozart, } \\
\text { Scarlatti, Beethoven). } \\
\text { Repertório [livre]: } 2 \text { peças } \\
\text { obrigatórias ( } 1 \text { de autor estrangeiro } \\
\text { e } 1 \text { de autor brasileiro). }\end{array}$ & $\begin{array}{l}\text { Duração - } 1 \text { semestre: } \\
\text { Repertório [obrigatório]: J. S. Bach, } \\
1 \text { Invenção a } 2 \text { vozes, } 1 \text { prelúdio e } \\
\text { fugueta; } 1 \text { Sonata Clássica; } 1 \text { obra de } \\
\text { Chopin (Mazurka, Prelúdio). } \\
\text { Repertório [livre]: } 1 \text { obra de autor } \\
\text { estrangeiro; } 1 \text { obra de autor } \\
\text { brasileiro. }\end{array}$ & $\begin{array}{l}\text { Piano } \\
\text { Técnico } \\
\text { IV }\end{array}$ \\
\hline $\begin{array}{l}\text { Piano } \\
\text { Técnico } \\
\text { IX }\end{array}$ & $\begin{array}{l}\text { Duração - } 1 \text { ou } 2 \text { semestres: } \\
\text { Repertório [obrigatório]: J. S. Bach, } \\
2 \text { invenções a } 2 \text { vozes; Sonata } \\
\text { (Haydn, Mozart, Scarlatti, } \\
\text { Beethoven), } 1 \text { sonata solo } \\
\text { completa; Chopin: Valsas, } \\
\text { Mazurkas, Noturnos, Polonaises - } 1 \\
\text { peça. } \\
\text { Repertório [livre]: } 2 \text { peças: } 1 \\
\text { brasileira e } 1 \text { romântica. }\end{array}$ & $\begin{array}{l}\text { Duração - } 1 \text { semestre: } \\
\text { Repertório [obrigatório]: J. S. Bach } \\
-1 \text { Invenção a } 3 \text { vozes; } 1 \text { Sonata } \\
\text { Clássica; } 1 \text { obra de Chopin } \\
\text { (Mazurka, Prelúdio, Valsa). } \\
\text { Repertório [livre]: } 1 \text { obra de autor } \\
\text { estrangeiro Séc. XX; } 1 \text { obra de autor } \\
\text { brasileiro. } \\
\text { Recital Solo: Bach, Sonata, Chopin, } \\
\text { obra de autor estrangeiro e } \\
\text { brasileiro. }\end{array}$ & $\begin{array}{l}\text { Piano } \\
\text { Técnico } \\
\text { V }\end{array}$ \\
\hline $\begin{array}{l}\text { Piano } \\
\text { Técnico } \\
\text { X }\end{array}$ & $\begin{array}{l}\text { Duração - } 1 \text { ou } 2 \text { semestres: } \\
\text { Repertório [obrigatório]: J. S. Bach, } \\
1 \text { invenção a } 3 \text { vozes; Sonata } \\
\text { clássica, } 1 \text { sonata solo completa. } \\
\text { Repertório [livre]: } 3 \text { peças } \\
\text { (brasileira, romântica, moderna). }\end{array}$ & $\begin{array}{l}\text { Duração - } 1 \text { semestre: } \\
\text { Repertório [obrigatório]: J. S. Bach, } \\
1 \text { Invenção a } 3 \text { vozes; } 1 \text { Sonata } \\
\text { Clássica, (Poderá ser a sonata do } \\
\text { período anterior); } 1 \text { obra de Chopin }\end{array}$ & $\begin{array}{l}\text { Piano } \\
\text { Técnico } \\
\text { VI }\end{array}$ \\
\hline
\end{tabular}




\begin{tabular}{|l|l|l|}
\hline Recital Solo (Formatura): 1 peça & (Mazurka, Prelúdio, Valsa, \\
de Bach; 1 sonata clássica; 1 peça & Noturno). \\
romântica; 1 peça moderna; 1 peça & Repertório [livre]: 1 obra de autor \\
brasileira; 1 peça a 4 mãos & estrangeiro do Séc. XX; 1 obra de \\
(opcional); 1 peça para BIS & $\begin{array}{l}\text { autor brasileiro. } \\
\text { (opcional). }\end{array}$ & $\begin{array}{l}\text { Recital Solo (Formatura): Bach, } \\
\text { Sonata, Chopin, obra de autor } \\
\text { estrangeiro e brasileiro. }\end{array}$ \\
\hline
\end{tabular}

Fonte: Programas do Curso Técnico de Piano - 2007 e 2018.

O Programa do Curso Técnico de Piano da EMEM foi reestruturado e passou a ser seguido pelos professores do Núcleo de Piano em 2002, após concurso público para “[...] Professor de Música de nível médio e a de Professor de Atividades Artísticas e Culturais de nível superior, para a qual foi exigido a formação específica na área de música [...]" (FERREIRA, 2017, p. 159). De acordo com Rodrigues (2020):

Com a nomeação dos novos professores, em 2002, o núcleo do curso de piano se organizou, propondo mudanças importantes para o funcionamento do curso: adoção obrigatória do Programa de Curso; nivelamento dos alunos; participação de todos os alunos nos recitais coletivos; realização de bancas de prova. (RODRIGUES, 2020, p. 72).

Desse modo, a partir de 2002, as provas de piano passaram a ser novamente obrigatórias mediante Banca Avaliadora com três professores, com a exigência de conteúdo técnico e repertório pré-definido do Programa e o não cumprimento dos requisitos levaria a reprovação do aluno. Antes do concurso, o conteúdo do Programa, isto é, a técnica, o repertório e as provas de piano, não eram cumpridas pelos próprios professores, principalmente os contratados, ficando a critério de cada um e "[...] essa autonomia docente atingia outros aspectos como a participação ou não em recitais de piano [...]" (SILVA, 2015, p. 183). Com isso, os alunos ficavam em defasagem na aprendizagem da técnica instrumental e no repertório pianístico, o que acarretava o abandono do Curso ou sua não conclusão.

Os campos em branco na coluna do Curso Técnico de Piano de 2018 corresponde ao que é estudado no Curso Fundamental, após a reestruturação curricular dos Cursos da EMEM. Importante frisar que o objetivo da comparação entre os programas de 2007 e 2018 é para analisar se houve realmente atualização do programa ou na verdade uma acomodação do repertório já estudado pelos alunos de 
Orepertório pianístico dos programas de recitais de alunos da $\operatorname{EMEM}(2001$-2010)

piano da Escola, após a criação do Curso Fundamental Adulto do referido instrumento.

Desse modo, o Programa de 2007 (antigo), era dividido em 10 períodos, para serem cumpridos em cinco anos, podendo a partir do piano VII ter a duração de um ou dois semestres, caso o aluno não conseguisse cumprir com os conteúdos exigidos. Nesse Programa e nos anteriores, o aluno de piano passava quase uma década para concluir o Curso de Piano, uma das razões, era porque muitos entravam no Curso, sem ter nenhuma base inicial no instrumento, ou não conseguiam chegar em um nível técnico satisfatório para cumprir com o conteúdo programático, entre outros.

A partir de então, o Programa do Curso Técnico de Piano passou por várias modificações com inserções significativas no que se refere a métodos de estudos, técnica, repertório, provas, recitais solos, entre outros. Um exemplo disso, no Programa de 2007, só era exigido a participação do aluno de piano em recital solo a partir do Piano VIII. Enquanto, no Programa de 2018, é exigido do aluno de piano, prova técnica, de repertório, além da presença em recitais solos feitos em duplas até o Piano Técnico IV e a partir do Piano Técnico V, os alunos deverão fazer recitais solos individuais. E sobre o recital solo individual

[...] o aluno deverá apresentar todo o repertório do período, podendo acrescentar peças de períodos anteriores. Os critérios de avaliação: Concentração, Postura de palco, Memorização, Controle emocional, Segurança, Estilo, Sonoridade. (PROGRAMA DO CURSO TÉCNICO DE PIANO, 2018, grifo dos autores).

Nesse sentido, o Programa de 2018 proporciona ao aluno do Curso Técnico de Piano não somente se preparar para ser capaz de executar o repertório exigido, mas também dá oportunidades para que desenvolva também a capacidade de se apresentar em público, de forma que vença os medos do palco e do público.

O Programa de 2018 (atual) ocorre em seis períodos de um semestre, tendo duração prevista para conclusão em três anos. Assim, o aluno de piano após ter cursado o Fundamental na instituição ou não, só poderá ingressar no Curso Técnico em Piano se obtiver aprovação por meio de processo seletivo, que consta de prova 
teórica, de percepção musical e de prova prática de instrumento. A prova prática de piano, conforme Edital N. 01/2019, consiste na execução de escalas, arpejos e acordes nas tonalidades maiores e menores; um estudo de Czerny; um prelúdio de Bach (23 peças fáceis); uma sonatina completa; uma peça de livre escolha pedalizada. Dessa forma, para entrar no Curso Técnico de Piano, o candidato já possui um nível técnico adiantado no instrumento. De acordo com o Edital N. 01/2019 Processo Seletivo Técnico da EMEM:

A Educação Profissional de Nível Técnico em Instrumento Musical e Técnico em Canto da Escola de Música do Estado do Maranhão "Lilah Lisboa de Araújo" destina-se à profissionalização musical dos candidatos que estejam regularmente matriculados no Ensino Médio ou que já o tenham concluído, que já possuam conhecimentos básicos de Teoria Musical, como também de Técnica Instrumental no instrumento para o qual pleiteia uma vaga na instituição. (ESCOLA DE MÚSICA DO ESTADO DO MARANHÃO, 2019, p. 01).

As mudanças realizadas com a criação do Curso Fundamental de Piano indicam a tentativa de cumprir o que previa o antigo programa de 2007 com a formação do aluno em nível técnico em cinco anos, tanto o aluno que estudou na EMEM desde os princípios básicos do piano, quanto os que ingressam já no nível técnico.

Nesse sentido é importante definir o que entendemos por repertório de piano, como um programa de peças e estudos de compositores pertencentes a vários períodos da história da música erudita ocidental europeia e brasileira, tradicional e contemporânea, que traz elementos característicos de cada estilo, como o gênero, a técnica, a forma, a dinâmica, entre outros, a serem executados pelos alunos pianistas nas aulas e nos recitais. De acordo com Hollerbach (2003) há dois tipos de repertório:

O termo 'repertório' aqui diz respeito a peças que os alunos aprendem e que eles tocam em audições e apresentações diversas. Diferencia-se do que chamamos 'repertório de leitura', que são peças trabalhadas com o objetivo de desenvolver a habilidade de leitura, sem a intenção de ser apresentadas em audições. (HOLLERBACH, 2003, p. 96).

Como demonstra no quadro 1, o repertório pianístico dos Programas de 2007 e 2018, corresponde a obras dos principais compositores, entre outros, dos períodos barroco (Bach, Scarlatti), do classicismo (Haydn, Mozart, Beethoven), do romântico (Beethoven, Chopin, Schumann), contemporâneo e brasileiro que não vem especificado. 
Orepertório pianístico dos programas de recitais de alunos da $\operatorname{EMEM}(2001$-2010)

No que se refere ao repertório pianístico do Curso Técnico de Piano, dos dois Programas analisados, embora nem tudo está explícito, assinalamos que dentro do repertório, há os compositores e obras obrigatórias como J. S. Bach (minuetos, prelúdios e fuguetas, invenções etc.); Schumann (Álbum para a Juventude op. 68); sonatinas (Clementi, Diabelli, Kuhlau, Gurlitt, Beethoven); sonatas barrocas e clássicas (Scarlatti, Haydn, Mozart, Beethoven); Chopin (mazurcas, prelúdios, valsas, noturnos), entre outros. Além de um repertório identificado como autor estrangeiro e brasileiro, este, deixa claro que é livre, fica a escolha do professor. Desse modo, nos Programas de 2007 e 2018, constatamos que o repertório é o mesmo, isto é, não difere muito, são os mesmos compositores, obras e gêneros de cada estilo musical, houve apenas uma reorganização destes em novos períodos, na nova configuração do Curso de Piano da EMEM, o Fundamental e o Técnico, antes o Técnico tinha a duração de cinco anos e atualmente passou para três anos.

\section{O repertório dos recitais de piano da EMEM}

O repertório consagrado ao piano continua datado e em grande modo parado e estabilizado no século XIX devido à profusão composicional dedicada a esse instrumento no dito século.

Durante o longo século XIX, cheio de contrastes, marcado por amplos movimentos políticos, econômicos, sociais e culturais, não é possível analisar esse contexto sem o Romantismo (1820 a 1910), no caso deste artigo, o romantismo musical. Nesse sentido, no mínimo duas questões devem ser levadas em consideração ao se enveredar por esse período: o primeiro diz respeito à periodização do movimento romântico europeu que segundo Kiefer $(1997 ; 2013)$ foi de 1810 até 1850 e após 1850, o pós-romantismo até o início do século XX. Indica ainda o autor que “[...] o movimento romântico só entrou com muito atraso em relação à Europa [...]" (KIEFER, 1997, p. 64). 
No entanto, segundo Volpe (2000) é necessário analisar o século XIX brasileiro a partir do que acontecia aqui, isto é, os acontecimentos políticos, econômicos e sociais, mas sem deixar de olhar para o que influenciava os compositores brasileiros, que era a música de tendência romântica europeia. Volpe (2000) afirma que todo o período que vai da chegada de D. João VI ao advento do modernismo é intitulado de romantismo. Tardiamente ou não, com perspectivas nacionalistas assumidas ou não, o romantismo musical no Brasil atravessou todo o século XIX.

Os principais centros musicais desse período foram o Rio de Janeiro, Bahia, São Paulo, entre outros. No Rio de Janeiro, entre os aspectos mais importantes da vida musical do período destacam-se: o surgimento de Sociedades Musicais e não Musicais, com o objetivo de promover concertos públicos; o piano como parte integrante da educação feminina burguesa; o uso, a fabricação e o comércio de instrumentos musicais; a criação do Conservatório de Música do Rio de Janeiro por Francisco Manuel da Silva (1795-1865); a presença de pianistas-compositores virtuoses internacionais, Arthur Napoleão em 1857 e Louis Moreau Gottschalk em 1869. E o repertório, consistia na música europeia, entre elas as danças: mazurcas, polcas, valsas, bem como a execução de obras de Mendelssohn, Schubert, Schumann, Thalberg, entre outros (KIEFER, 1997).

Apesar da preponderância da Corte Imperial no que tange ao movimento artístico-cultural, na capital maranhense também existiam professores de piano que vinham com as companhias líricas estrangeiras que davam espetáculo no Teatro São Luís, além de professores e professoras de piano brasileiros nascidos ou radicados no Maranhão ao longo das últimas décadas do século XIX e pelo século XX (GOUVEIA NETO, 2010).

É justamente no século XIX que o piano alcança o auge de sua perfeição, trazendo inovações na produção, extensão, versatilidade, sonoridade, intensidade, expressividade, tessitura, técnica, bem como sua popularização. Medaglia (2008, p. 120), afirma que "surge nesse período também a figura do pianista-compositor, verdadeiros malabaristas do instrumento que arrebatavam plateias com o virtuosismo de suas obras, criadas para que eles mesmos as apresentassem em público”. Entre os virtuoses desse período, destaca-se o compositor e pianista-concertista Franz Liszt 
Orepertório pianístico dos programas de recitais de alunos da EMEM(2001 -2010)

(1811-1886), que inovou na técnica, inventou o recital de piano e o modo de tocá-lo em público e transformou a música para piano, em um grau de excelência (BLANNING, 2011).

QUADRO 2 - LISTA DE COMPOSITORES DE PIANO EXECUTADOS NOS RECITAIS DE PIANO NA EMEM - 2001 A 2010

\begin{tabular}{|c|c|}
\hline Compositores & Número de peças executadas \\
\hline L. V. Beethoven (1770-1827) & 16 \\
\hline C. M. V. Weber (1786-1826) & 01 \\
\hline Friedrich Kuhlau (1786-1832) & 04 \\
\hline Franz Schubert (1797-1828) & 03 \\
\hline Friedrich Burgmüller (1806-1874) & 04 \\
\hline Felix Mendelssohn (1809-1847) & 07 \\
\hline Frédéric Chopin (1810-1849) & 28 \\
\hline Robert Schumann (1810-1856), & 21 \\
\hline Charles Gounod (1818-1893) & 01 \\
\hline Cornelius Gurllit (1820-1901) & 06 \\
\hline César Frank (1822-1890) & 01 \\
\hline Johannes Brahms (1833-1897) & 04 \\
\hline P. I. Tchaikovsky (1840-1893) & 01 \\
\hline Edvard Grieg (1843-1907) & 01 \\
\hline Moritz Moszkowski (1854-1925) & 06 \\
\hline Isaac Albeniz (1860-1909) & 01 \\
\hline Claude Debussy (1862-1918) & 05 \\
\hline Erik Satie (1866-1925) & 02 \\
\hline Sergei Rachmaninoff (1873-1943) & 01 \\
\hline Bela Bartók (1881-1945) & 01 \\
\hline Carlos Gomes (1836-1896) & 03 \\
\hline Francisca Gonzaga (1847-1935) & 05 \\
\hline Henrique Oswald (1852-1931) & 01 \\
\hline Antônio Rayol (1863-1904) & 01 \\
\hline Ernesto Nazareth (1863-1934) & 29 \\
\hline João Nunes (1877-1951) & 01 \\
\hline Zequinha de Abreu (1880-1935) & 03 \\
\hline Heitor Villa-Lobos (1887-1959) & 24 \\
\hline João Octaviano (1892-1962) & 01 \\
\hline Lorenzo Fernandez (1897-1948) & 05 \\
\hline Francisco Mignone (1897-1986) & 03 \\
\hline Guilherme Leanza (1909-1985) & 02 \\
\hline Clarisse Leite (1917-2003) & 01 \\
\hline Mário Mascarenhas (1929-1992) & 04 \\
\hline
\end{tabular}

Fonte: Programas dos Recitais de Piano entre 2001 e 2010.

A partir do quadro 2 percebemos que o repertório dos recitais dos alunos de piano da EMEM entre 2001 e 2010 consultados apresentam 21 compositores Rev. Caminhos da Educação: diálogos, culturas e diversidades, Teresina, v. 3, n. 1, p. 103-124, Jan./Abr. 2021 
estrangeiros, 14 compositores brasileiros, entre eles duas mulheres, Francisca Gonzaga e Clarice Leite e dois compositores maranhenses, Antônio Rayol e João Nunes.

Destacamos, também, a ausência de compositores maranhenses no repertório pesquisado, tais como, Leocádio Rayol, Antônio Rayol, Elpídio Pereira, Ignácio Cunha, João Nunes, entre outros. Nos programas dos Recitais de Piano consultados aparecem os compositores Antônio Rayol com uma peça executada por um dos autores deste artigo, a valsa Vera Lowndes e, João Nunes, também com uma peça intitulada A boneca desprezada da coleção Peças Infantis. De acordo com Silva (2015, p. 121 122), “João Nunes é uma daquelas personalidades históricas pouco reconhecidas em sua cultura de origem. Embora tendo sido muito apreciado em sua época por seus conterrâneos maranhenses, na atualidade, poucos o reconhecem como tal [...]". Fato este, suas obras não estão no conteúdo programático obrigatório de piano, raramente nos recitais, pois como informado acima, o repertório é de livre escolha do professor de piano, na categoria autor brasileiro.

A pianista maranhense Zezé Cassas, divulgadora da obra de João Nunes em seus concertos realizou recital de piano solo, em 23 de novembro de 2009, interpretando composições de João Nunes, lançamento do CD “Zezé Cassas interpreta João Nunes", segundo álbum da pianista. Evento ocorrido durante a III Semana de Piano da EMEM, no repertório, as obras: Os Três Meninos (3), Parque de Diversões (6), Peças Infantis (6), Quatro Peças Fáceis (4) e Caixinha de Música, totalizando 20 peças executadas (SEMANA DE PIANO, 2009). Algumas dessas obras são didáticas, por isso, poderiam estar inclusas no repertório do Programa do Curso Técnico de Piano.

Entre os 35 compositores que constam nos 22 programas de recitais de piano consultados elencamos os 5 mais executados conforme quadro 3. De certo modo isso reflete a proporção entre compositores estrangeiros e brasileiros e vai ao encontro, às exigências tanto do Programa do Curso de Piano de 2007 quanto de 2018, apesar de os dados serem anteriores à última atualização do currículo do Curso Técnico de Piano da EMEM. 
Orepertório pianístico dos programas de recitais de alunos da EMEM(2001 -2010)

QUADRO 3 - LISTA DE COMPOSITORES DE PIANO COM PEÇAS MAIS EXECUTADAS NOS RECITAIS DA EMEM 2001 A 2010

\begin{tabular}{|c|c|}
\hline Compositor & Gênero/Peças \\
\hline L. V. Beethoven viii & Valsas, Sonatinas, Sonatas \\
\hline Frédéric Chopin ${ }^{\mathrm{ix}}$ & Mazurcas, Prelúdios, Valsas, Noturnos \\
\hline Robert Schumann ${ }^{\mathrm{x}}$ & Álbum para a Juventude op. 68 \\
\hline Ernesto Nazareth ${ }^{\mathrm{xi}}$ & Choros, Polcas, Tangos, Valsas \\
\hline Heitor Villa-Lobos ${ }^{\mathrm{xii}}$ & $\begin{array}{l}\text { Brinquedos de Rodas, Cirandinhas, } \\
\text { Cirandas, Petizadas, Prelúdio da Bachiana } \\
\text { N. } 4\end{array}$ \\
\hline
\end{tabular}

Fonte: Programas dos Recitais de Piano entre 2001 e 2010.

Os cinco primeiros compositores mais executados nos recitais de alunos da EMEM conforme quadro 3 indicam que o repertório do Curso Técnico de Piano desta Instituição mesmo com as reformulações feitas no século XXI, ratificam a continuidade do tipo de música composta para o piano ao longo do século XIX e primeiras décadas do século $\mathrm{XX}$, sendo os três primeiros compositores típicos do repertório pianístico europeu. Os dois últimos, brasileiros, ratificam também o que a literatura musicológica tem demonstrado ao longo dos últimos anos como os compositores que expressam os melhores exemplos de transposição, adaptação e criação de novas estéticas a partir do modelo europeu (MACHADO, 2007).

No repertório dos programas analisados dos Recitais de Piano realizados na EMEM no período de 2001 a 2010, representados no quadro 2, aparecem diversos compositores desses períodos citados, mas alguns não estão especificados nos Programas de 2007 e 2018, conforme quadro 1, pois estão categorizados como autor estrangeiro e autor brasileiro. Assinalamos que a escolha de repertório para essas categorias nos Programas dos recitais mencionados está relacionado ao planejamento didático de cada professor, que conhece o nível técnico de seu aluno, ou seja, é de competência do professor "saber reconhecer em que estágio de desenvolvimento o aluno poderá tocar uma peça específica, para quais exigências técnicas e interpretativas ele está preparado ou quais as habilidades necessárias para a execução de determinado repertório” (ZORZETTTI, 2010, p. 730). 
No entanto, seria relevante a especificação de compositores nas categorias: autor estrangeiro, autor brasileiro (principalmente os do presente), compositores do século XX (europeus, brasileiros) e suas obras no Programa de Piano atual, para estabelecer um repertório referencial por níveis de dificuldades para o professor, assim como estão classificadas as obras do compositor J. S. Bach por ordem de dificuldades nos Programas. Zorzetti (2010, p. 735) fez um levantamento de peças de compositores brasileiros, apresentando um quadro que indica autor, obra, utilização de aspectos da cultura nacional e aspectos da execução pianística, com o objetivo de subsidiar o professor na seleção de repertório brasileiro para piano, direcionado aos alunos iniciantes no instrumento, ou seja, no nível elementar:

Villa-Lobos (1887-1959), Petizada, Brinquedo de Roda, Cirandinhas; Dinorá de Carvalho (18951980), 11 Peças Infantis sobre Motivos Populares; Lorenzo Fernandez (1897-1948), Na beira do rio; Guerra-Peixe (1914-1993), 1 ${ }^{a}$ Suíte Infantil; Ernst Widmer (1927-1990), Ludus Brasiliensis, Kosmos Latinoamericano; Osvaldo Lacerda (1927-2011), Valsinha Brasileira; Edino Krieger (1928), Choro Manhoso, Estudo Seresteiro; Ernst Mahle (1929), Vamos Maninha; Henrique Morozowicz (1934-2008), Primeiro Caderno de Karina; Sérgio de Vasconcellos Corrêa (1934), Suíte Infantil $n^{\circ} 1$, Suíte Infantil no 2; Willy Corrêa de Oliveira (1938), Nove Peças Fáceis, 7 ou 8 Peças (mais) Fáceis; Calimério Soares (1944-2011), Sambinha; Moema Craveiro Campos (1947), 13 Pequenas Peças Brasileiras; Ronaldo Miranda (1948), Requebradinho; João Guilherme Ripper (1959), Três Pequenos Estudos; Dimitri Cervo (1968), Pequena Suíte Brasileira. (ZORZETTI, 2010, p. 735).

A partir das indicações da autora percebemos que o repertório do Curso de Piano da EMEM é bem diferente, o que ratifica as escolhas individuais e coletivas de um grupo de professores em relação ao aprendizado de um determinado instrumento musical, para além dos compositores considerados indispensáveis como já citamos aqui. Desse repertório acima, encontramos nos programas dos Recitais de Piano da EMEM, as peças de Villa-Lobos: Brinquedo de Roda, Cirandinhas, Petizada. Além das obras do compositor Lorenzo Fernandez: Despertar $\mathrm{N}^{\circ}$ 1, Acalanto $\mathrm{N}^{\circ}$ 3, Roda $N^{o}$ 4, da Suíte das Cinco Notas; A camponesa Italiana No 3, da Suíte Bonecas e Velha Modinha da Primeira Suíte Brasileira.

No Programa de 2018, a partir do Piano Técnico V, vem como exigência uma obra de autor estrangeiro do século XX, porém, como supracitado, os compositores não vêm especificados. As obras dos compositores do século XX encontrados no repertório dos programas dos Recitais de Piano foram: Béla Bartók, Debussy e entre os compositores brasileiros: outros. Outro aspecto, de grande relevância, é incluir nessa categoria (autor estrangeiro), compositores contemporâneos, aqueles que estão Rev. Caminhos da Educação: diálogos, culturas e diversidades, Teresina, v. 3, n. 1, p. 103-124, Jan./Abr. 2021 
Orepertório pianístico dos programas de recitais de alunos da $\operatorname{EMEM}(2001$-2010)

compondo no presente, para que o aluno pianista tenha conhecimento da produção e do repertório da música atual. A este respeito Deltrégia (1999) afirma:

[...] é fundamental que o aluno iniciante [e avançado] conheça a música mais recente, não apenas para enriquecer suas possibilidades de escolha e ter contato com a estética musical de sua época, mas também para desenvolver precocemente o potencial criativo que a interpretação desse repertório possibilita [...]. (DELTRÉGIA, 1999, p. 05).

\section{Considerações finais}

Analisar o repertório de um instrumento centenário como o piano que possui um caminho sonoro consolidado no mundo ocidental, mesmo restrito aos programas dos recitais dos alunos do Curso de Piano da EMEM, não é tarefa para um único artigo. Assim, este texto é o primeiro movimento que pretendemos realizar sobre o repertório pianístico institucionalizado na única escola de piano de nível técnico do Estado do Maranhão.

Apesar disso, neste estudo encontramos os compositores mais famosos do repertório pianístico europeu do século XIX soando também pelas casas dos maranhenses estudantes da EMEM. Indicamos a presença quase imperceptível dos compositores maranhenses no repertório no Curso de Piano da Escola, mesmo havendo a obrigatoriedade da execução de uma peça de autor brasileiro que é restrito aos compositores brasileiros consagrados no eixo Rio-São Paulo.

Nesse sentido, indicamos a importância de mais estudos e análises sobre a ressignificação do repertório pianístico na EMEM não somente dando visibilidade e deixando soar os compositores maranhenses que escreveram música para o piano durante o século XIX e início do XX, assim como os compositores brasileiros atuais.

\section{Referências}

BLANNING, T. O triunfo da música: a ascensão dos compositores, dos músicos e de sua arte. Tradução de Ivo Korytowski. São Paulo: Companhia das Letras, 2011. 
DELTRÉGIA, C. A composição musical e o ensino do piano no Brasil: uma breve reflexão. In: Congresso Anual da Associação Nacional de Pesquisa e Pós-Graduação em Música, 12., 1999, Salvador. Anais do XII Congresso da ANPPOM. Salvador: ANPPOM, 1999. p. 01-09.

ESCOLA DE MÚSICA DO ESTADO DO MARANHÃO - Lilah Lisboa de Araújo. Secretaria de Estado da Cultura e Turismo. Programa do curso técnico de piano. São Luís: EMEM, 2007.

Programa do curso técnico de piano. São Luís: EMEM, 2018.

EDITAL $N^{o} 01 / 2015$ Processo Seletivo Simplificado para ingresso de alunos ao Curso Fundamental de Música nas modalidades Infantil e Adulto e ao Curso de Musicalização de acordo com a legislação vigente. São Luís, MA, p. 01-06, jun. 2015. Disponível em: http://casas.cultura.ma.gov.br/portal/sgc/modulos/sgc_emem/noticia/arq_noticia/2015. 06.05-Edital_Fundamental.pdf. Acesso em: 02 abr. 2021.

EDITAL No 01/2019 Processo Seletivo. Estabelece o período de inscrição para o processo seletivo para os Cursos Técnicos Profissionalizantes em Instrumento Musical e em Canto na Escola de Música do Estado do Maranhão. São Luís, MA, p. 01-10, jan. 2019. Disponível em: http://casas.cultura.ma.gov.br/emem/index.php?page=edital_estendido\&id=8. Acesso em: 27 jan. 2021.

EDITAL $N^{o}$ 01/2020 Processo Seletivo. Estabelece o período de inscrição para o processo seletivo para os Cursos Técnicos em Instrumento Musical e em Canto na Escola de Música do Estado do Maranhão. São Luís, MA, p. 01-8, 29 jan. 2020. Disponível em: http://casas.cultura.ma.gov.br/portal/sgc/modulos/sgc_emem/edital/edital_arquivo/202 0.02.06-Edital-Te_769_cnico-2020-EMEM.pdf. Acesso em: 02 abr. 2021.

FERrEIRA, A. N. A. A Escola Lilah Lisboa de Araíjo: o ensino de música no Nordeste e no Maranhão. São Luís: EDUFMA, 2017.

GOUVEIA NETO, J. C. Ao som de pianos flautas e rabecas... Estudo das vivências musicais das elites na São Luís da segunda metade do século XIX. 2010. 168 f. Dissertação (Mestrado em História do Brasil) - Programa de Pós-Graduação em História do Brasil, Universidade Federal do Piauí, Teresina, 2010.

A Importância do Jornal A Luta na construção da imagem musical de Antônio Rayol como O Tenor Maranhense na segunda metade do Século XIX em São Luís. VI Simpósio Nacional de História Cultural Escritas da História: Ver - Sentir - Narrar Universidade Federal do Piauí - UFPI, Teresina-PI, 2012. Disponível em: http://gthistoriacultural.com.br/VIsimposio/anais/Joao $\% 20 \operatorname{Costa} \% 20$ Gouveia $\% 20$ Neto. pdf.

GOUVEIA NETO, J. C.; NAVARRO, A. G; CASTRO, C. A. Espaços de ensino musical na São Luís da segunda metade do século XIX. Revista Olhares, v. 7, n. 3, p. 189 - 200, Guarulhos, nov. 2019. Disponível em: https://periodicos.unifesp.br/index.php/olhares/article/view/9632 
Orepertório pianístico dos programas de recitais de alunos da $\operatorname{EMEM}(2001$-2010)

HOLLERBACH, I. Ensino elementar de piano: princípios didáticos, objetivos e escolha de repertório na perspectiva do professor de piano. 2003. 147f. Dissertação (Mestrado em Música) - Universidade Federal de Minas Gerais, Belo Horizonte, 2003.

KIEFER, B. História da música brasileira: dos primórdios ao início do século XX. 4. ed. Porto Alegre: Movimento, 1997. (Coleção Luis Cosme; v. 9).

O romantismo na música. In: GUINSBURG, J. (Org.). O romantismo. $3^{\text {a }}$ reimpressão da $4^{a}$ ed. 2002. São Paulo: Perspectiva, 2013.

MACHADO, C. O enigma do homem célebre: ambição e vocação em Ernesto Nazareth. São Paulo: Instituto Moreira Salles, 2007.

MEDAGLIA, J. Música, maestro: do canto gregoriano ao sintetizador. 1. ed. São Paulo: Globo, 2008.

RODRIGUES, A. L. S. F. Reflexões sobre habilidades Criativas no Curso Fundamental Infantil de Piano da EMEM: um estudo de caso. 2020. 180f. Dissertação (Mestrado) - Programa de PósGraduação em Rede - Prof-Artes em Rede Nacional/CCH, Universidade Federal do Maranhão, São Luís, 2020.

SEMANA DE PIANO, 3., 2009, São Luís. Folder... São Luís: EMEM, 23 nov. 2009.

SILVA, P. F. Uma história do piano em São Luís do Maranhão. São Luís: EDUFMA, 2015.

TRIPP, D. Pesquisa-ação: uma introdução metodológica. Educação e Pesquisa, São Paulo, v. 31, n. 3, p. 443-466, set./dez. 2005.

VOLPE, M. A. Algumas considerações sobre o conceito de Romantismo musical no Brasil. Brasiliana, n.8, maio 2000.

ZORZETTI, D. Música brasileira para o ensino do piano no nível elementar. In: I SIMPÓSIO BRASILEIRO DE PÓS-GRADUANDOS EM MÚSICA. XV Colóquio do Programa de Pós-Graduação em Música da UNIRIO: Pesquisa em música: novas conquistas e novos rumos. 1., 2010, Rio de Janeiro. Anais... Rio de Janeiro: UNIRIO, 08 a 10 nov. 2010. p. $728-737$.

RECEBIDO: 31/03/2021

APROVADO: $17 / 04 / 2021$
RECEIVED: $31 / 03 / 2021$

APPROVED: $17 / 04 / 2021$
RECIBIDO: 31/03/2021

APROB ADO: $17 / 04 / 2021$ 
i José Ribamar Belo Martins, cantor lírico, estudou canto nos Estados Unidos. Foi presidente da Fundação Cultural do Maranhão (FUNC) em 1971, no Governo de Pedro Neiva Santana.

ii Antônio Rayol (1863-1904), cantor lírico e compositor maranhense, nasceu em São Luís/MA, em uma família de músicos, tendo como irmãos Leocádio e Alexandre Rayol.

iii João Nunes (1877-1951), pianista concertista, professor de piano e compositor maranhense, natural de São Luís/Ma.

iv Maria José Duailibe Cassas Gomes ou Zezé Cassas (1939), pianista concertista e professora de piano, natural de São Luís/MA, estudou piano com Lilah Lisboa de Araújo (MA) e formou-se em piano pela Escola Nacional de Música no Rio de Janeiro, em 1958.

${ }^{v}$ Lilah Lisboa de Araújo (1898-1979), foi pianista e professora de piano em São Luís/MA, estudou música em Portugal e na Inglaterra. No Brasil, estudou no Instituto Nacional de Música (RJ), foi aluna de Heitor Villa-Lobos.

${ }^{\text {vi }}$ As vagas para bandolim só constam no Edital 01/2015- EMEM, não estando mais disponível nos editais seguintes para ingresso de novos alunos para o dito instrumento.

vii A nomenclatura desse curso varia entre os editais consultados, mas é o mesmo Curso.

viii L. V. Beethoven (1770-1827), pianista e compositor alemão, vivenciou dois períodos da história da música, o final do Classicismo e o início do Romantismo. Sua produção musical contém canções, concertos, missas, óperas, sinfonias, música de câmara e para piano etc.

ix Frédéric Chopin (1810-1849), foi um pianista compositor mais expressivo do Romantismo, nascido na Polônia, mas viveu boa parte de sua vida em Paris, até sua morte. Foi professor de piano e executou suas composições em concertos públicos. Sua obra é inteiramente para piano.

${ }^{x}$ Robert Schumann (1810-1856), músico, compositor, crítico musical alemão, foi um dos expoentes do Romantismo, pois imprimiu na sua música a poesia e a literatura de seu tempo. Estudou piano com Friedrich Wieck, porém, não foi um concertista, pois perdera os movimentos da mão esquerda devido a uma doença degenerativa. Em 1840, casou-se com a famosa pianista e compositora Clara Wieck, filha de seu professor de piano.

${ }^{x i}$ Ernesto Nazareth (1863-1934), nascido no Rio de Janeiro, pianista e compositor brasileiro, um pioneiro da música nacionalista do Brasil. Sua obra pianística, constitui-se de choros, polcas, quadrilhas, sambas, tangos brasileiros, valsas, entre outras.

xii Heitor Villa-Lobos (1887-1959), compositor nacionalista da música erudita brasileira, foi professor e maestro, nascido e falecido no Rio de Janeiro. Foi um compositor autodidata, criando seu próprio estilo de composição. Viajou pelo Brasil, coletando temas do folclore e da música popular brasileira. Em 1922, participou da Semana de Arte Moderna, em São Paulo. Villa-Lobos, viajou pela Europa e Estados Unidos, divulgando sua música. De retorno ao Brasil, durante o Governo Getúlio Vargas (1930-1945), implantou o Canto Orfeônico nas escolas públicas brasileiras, em 1931. 